\title{
Has climate change resulted in a mismatch between the spring arrival of the Common Cuckoo Cuculus canorus and its hosts in North Norway?
}

\author{
Robert T. Barrett
}

Department of Natural Sciences, Tromsø University Museum, PO Box 6050 Langnes, NO-9037 Tromsø, Norway; rob.barrett@uit.no

\begin{abstract}
Analysis of spring arrival dates in North Norway showed advanced arrival of the Common Cuckoo Cuculus canorus but not of four of its most frequently used hosts. No evidence was found of a climate-driven mismatch that might contribute to the decline in the Norwegian Cuckoo population.
\end{abstract}

Key words: climate change; migration; arrival date; brood parasite; population change

\section{INTRODUCTION}

The Common Cuckoo Cuculus canorus (hereafter Cuckoo) is common throughout Norway, although its presence seems to diminish with increasing latitude (Gjershaug et al. 1994). How many Cuckoos breed in Norway is unknown (possibly in the order of 50 000-100 000 pairs, Gjershaug et al. 1994), but the Norwegian population has, as in much of Europe, declined significantly since 1996 (Erritzøe \& Mann 2012, Kålås et al. 2014, Moksnes 2014). Causes of this decline are unclear and may be related to resource availability in the Cuckoos' wintering quarters, along their migration routes and/or in the breeding area, or to declines in the abundance of their hosts (Douglas et al. 2010, Erritzøe \& Mann 2012). There is also evidence to show that climate change might be disrupting the close association between the migration and breeding phenology of the Cuckoo and its hosts resulting in a mismatch in their respective nesting times (Saino et al. 2009, Møller et al. 2011). Whereas the Cuckoo, itself a long-distance migrant wintering south of the Sahara in Africa, seems to be keeping track of the phenology of other long-distance, migratory hosts, this mismatch is especially evident between the Cuckoo and its shortdistance migrant hosts that winter in Europe or North Africa (Saino et al. 2009). This may be a result of shortdistant migrants tending to advance their spring arrival more than long-distance migrants and thus starting to nest before the cuckoos have arrived (e.g. Rubolini et al. 2007, Rainio et al. 2006).

Whereas the lack of data concerning resources in the winter quarters or along the migration routes and of population changes of host species of Norwegian Cuckoos precludes any analysis of these factors on the population decline in Norway (Moksnes 2014), spring arrival data collected by members of the public and the Norwegian Ornithological Society (e.g. Barrett 2002) does allow one to address the possibility of the development of a mismatch in the migration phenologies of the Cuckoo and its hosts. This study addresses Moksnes' (2014) hypothesis that the decline in the Norwegian Cuckoo population may be partly explained by a climate-change-induced increase in mismatch in arrival times between the Cuckoo and its hosts in North Norway where there is evidence of a recent climate-related advancement of arrival dates among many species and where medium-distance migrants have advanced their arrival dates by $>0.5 \mathrm{~d}$ $\mathrm{yr}^{-1}$ faster than long-distance migrants over a ca. $15 \mathrm{yr}$ period (Barrett 2011).

\section{MATERIAL AND METHODS}

Making up $65 \%$ of all registered episodes of Cuckooparasitism in Norway, the Meadow Pipit Anthus pratensis is by far the most common host of the Cuckoo in Norway, with the Whinchat Saxicola rubetra (7\%) and Bluethroat Luscinia svecica (4\%) taking the two next places (Moksnes et al. 2011). With the Meadow Pipit again first on the list in Troms, Strann \& Bakken (2004) also highlight the Dunnock Prunella modularis, Brambling Fringilla montifringilla and Common Redstart Phoenicurus phoenicurus as common hosts in this North Norwegian county, but these each constitute $<1.5 \%$ of the national average (Moksnes et al. 2011). North of Troms, in Finnmark, the Meadow Pipit, Bluethroat and Brambling are cited at hosts (Frantzen et al. 1991). 
Table 1. Arrival date (based on first observations in the complete data base) and time trend analyses (linear and segmented piecewise regression, based on date of second record) of arrival dates of the Cuckoo and four of its hosts in Troms, northern Norway between 1980 and 2013. $\mathrm{n}=$ sample size and significant values $(\mathrm{p}<0.05)$ are shown in bold.

\begin{tabular}{|c|c|c|c|c|c|c|c|c|c|c|}
\hline \multirow[t]{2}{*}{ Species } & \multirow[t]{2}{*}{ Type } & \multicolumn{2}{|c|}{ Arrival date } & \multicolumn{3}{|c|}{ Linear regression } & \multicolumn{4}{|c|}{ Segmented piecewise regression } \\
\hline & & Median & $\mathrm{n}$ & Slope & $r^{2}$ & $\mathrm{p}$ & Break & $r^{2}$ & $\mathrm{p}$ & $\mathrm{n}$ \\
\hline Common Cuckoo & $\mathrm{L}$ & 18 May & 34 & -0.30 & 0.37 & 0.000 & 1997 & 0.42 & 0.000 & 33 \\
\hline Meadow Pipit & $\mathrm{M}$ & 29 April & 31 & -0.20 & 0.14 & 0.059 & - & 0.07 & 0.196 & 26 \\
\hline Dunnock & M & 24 April & 31 & -0.47 & 0.35 & 0.000 & 1996 & 0.37 & 0.000 & 30 \\
\hline Bluethroat & $\mathrm{L}$ & 16 May & 27 & -0.26 & 0.16 & 0.036 & - & 0.14 & 0.051 & 27 \\
\hline Brambling & M & 9 April & 36 & -1.11 & 0.63 & 0.000 & 1996 & 0.70 & 0.000 & 34 \\
\hline
\end{tabular}

Since the 1970 s, the timing of spring arrivals of nearly 100 species migrating to North Norway has been recorded every year by keen bird watchers and members of the regional branch of the Norwegian Ornithological Society, and all the data (including those gleaned from http://artsobservasjoner.no) are stored at Tromsø Museum (Barrett 2002, 2003). This analysis is based on data collected in Troms since 1980 by which time reports were arriving in a more systematic manner.

As in an earlier analysis (Barrett 2011), this study was restricted to species for which there was a minimum observation set of four arrival dates in four different localities in any one year, and a minimum sample size of 15 years. First sighting or auditory records were used as a proxy of arrival dates but the possibility of including overwintering birds or extreme early arrivals of outlying "rogue" individuals (Sparks et al 2001) was reduced by basing trend analyses on the dates of the second individual(s) was seen or heard. As a control, the same analyses were also carried out using the observation dates of the third individual. In the latter case, all records were in localities different to those of the second observation, thus avoiding any possibility of pseudoreplication through successive records of the same individual.

The initial time-trend analysis consisted of a simple linear regression analysis of arrival date of species to
Troms against year but, as in Barrett (2011) this was followed by a segmented piecewise regression analysis applied to each data set using the interactive method downloaded in 2010 from the Excel Resources web page at http://processtrends.com/downloads.htm (D. Kelly O'Day).

This study addresses the arrival time of the Cuckoo with four of its potential hosts, the Meadow Pipit (main host) and Dunnock, Bluethroat and Brambling (minor hosts). There was insufficient data to include the Whinchat and Common Redstart.

\section{RESULTS}

The first Cuckoos and Bluethroats (both long-distance migrants) arrive in North Norway in the middle of May, 2-3 weeks after the Meadow Pipit and Dunnock and more than one month after the first Bramblings (Table 1). The latter three species are usually defined as shortdistance migrants, but by the time they reach North Norway they are better described as medium-distance migrants. Using the dates of the second arrivals, the arrival date of the Cuckoo advanced at a mean rate of $0.3 \mathrm{~d} \mathrm{yr}^{-1}$ between 1980 and 2012, but the segmented regression analysis revealed a significant break point in 1997 (Table 1), before which there was no advance and

Table 2. Time trend analyses of arrival dates before and after the piecewise regression breakpoints given in Table 1 of the Cuckoo and two of its hosts in Troms, northern Norway between 1980 and 2013. $\mathrm{n}=$ sample size and significant values $(\mathrm{p}<0.05)$ are shown in bold.

\begin{tabular}{|c|c|c|c|c|c|c|c|c|c|}
\hline \multirow[t]{3}{*}{ Species } & \multirow{3}{*}{$\begin{array}{l}\text { Break } \\
\text { point }\end{array}$} & \multicolumn{8}{|c|}{ Segmented piecewise regression (1980-2013) } \\
\hline & & \multicolumn{4}{|c|}{ Before break } & \multicolumn{4}{|c|}{ After break } \\
\hline & & Slope & $\mathrm{r}^{2}$ & $\mathrm{p}$ & $\mathrm{n}$ & Slope & $\mathrm{r}^{2}$ & $\mathrm{p}$ & $\mathrm{n}$ \\
\hline Common Cuckoo & 1997 & -0.09 & 0.01 & 0.658 & 17 & -0.66 & 0.46 & 0.005 & 17 \\
\hline Dunnock & 1996 & -0.40 & 0.05 & 0.447 & 13 & -0.82 & 0.46 & 0.002 & 18 \\
\hline Brambling & 1996 & -0.35 & 0.05 & 0.378 & 16 & -1.78 & 0.60 & 0.000 & 19 \\
\hline
\end{tabular}




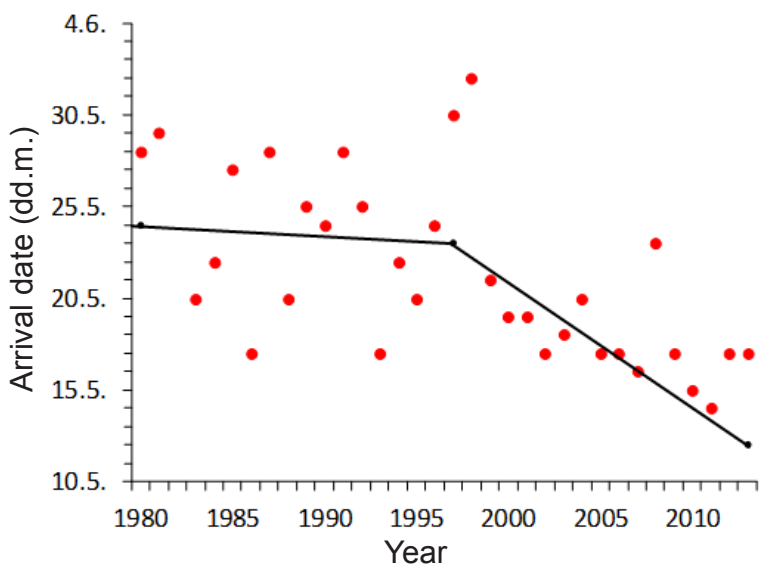

Figure 1. Arrival dates (of the second bird) of the Common Cuckoo in Troms, North Norway, 1980-2013. The segmented piecewise regression lines show no change until 1997, after which arrival dates advanced significantly (see Tables 1 and 2).

after which the advance was $0.7 \mathrm{~d} \mathrm{yr}^{-1}$ (Table 2, Figure 1). There was, despite a tendency towards an advance in dates, no evidence of any change in the arrival date of the Cuckoo's main host, the Meadow Pipit (Table 1). The three less important hosts all advanced their arrival between 1980 and 2012 at rates of $0.3-1.1 \mathrm{~d} \mathrm{yr}^{-1}$ (Table 1) with the Brambling and Dunnock showing no change until 1996, after which they tended to arrive earlier at rates of 1.8 and $0.8 \mathrm{~d} \mathrm{yr}^{-1}$ respectively (Table
2). This pattern was repeated when the analyses were based on the dates of the third arrivals (Tables 3 and 4).

\section{DISCUSSION}

Earlier studies have suggested that a more rapid advance in arrival dates and the implicit advance in the initiation of breeding of short-distance migrant hosts in response to increases in temperature than that of the Cuckoo may result in a decrease in availability of host nests and thus contribute to the population decline of the latter (Saino et al. 2009, Møller et al. 2011, Balmer et al. 2013). This study, however, documents a significant advance of arrival dates of the Cuckoo to North Norway over a 30 year period, with an acceleration since 1997 but not so of its main host the Meadow Pipit. As such, the Cuckoo can only have gained an advantage over its main host by arriving earlier. This discrepancy corroborates Jonzén et al. (2006) findings that at least some longdistance migrants have, in fact, advanced their arrival in Scandinavia more that short-distance migrants, although the Cuckoo was not included in their analysis.

As for the three less important hosts, the there was no evidence of a change of arrival date of the Bluethroat, while the Dunnock showed similar patterns to that of the Cuckoo. The arrival of the Brambling, on the other hand, has advanced at over twice the rate $\left(1.8 \mathrm{~d} \mathrm{yr}^{-1}\right)$ of that of the Cuckoo since the late 1990s. Unless the

Table 3. Time trend analyses (linear and segmented piecewise regression, based on date of third record) of arrival dates of the Cuckoo and four of its hosts in Troms, northern Norway between 1980 and 2013. $\mathrm{n}=$ sample size and significant values $(\mathrm{p}<0.05)$ are shown in bold.

\begin{tabular}{|c|c|c|c|c|c|c|c|}
\hline \multirow[t]{2}{*}{ Species } & \multicolumn{3}{|c|}{ Linear regression } & \multicolumn{4}{|c|}{ Segmented piecewise regression } \\
\hline & Slope & $r^{2}$ & $\mathrm{p}$ & Break & $\mathrm{r}^{2}$ & $\mathrm{p}$ & $\mathrm{n}$ \\
\hline Common Cuckoo & -0.35 & 0.41 & 0.000 & 1997 & 0.46 & 0.000 & 33 \\
\hline Meadow Pipit & -0.16 & 0.09 & 0.126 & - & 0.11 & 0.097 & 26 \\
\hline Dunnock & -0.44 & 0.30 & 0.002 & 1996 & 0.36 & 0.000 & 30 \\
\hline Bluethroat & -0.24 & 0.20 & 0.019 & - & 0.27 & 0.054 & 27 \\
\hline Brambling & -1.02 & 0.64 & 0.000 & 1999 & 0.69 & 0.000 & 34 \\
\hline
\end{tabular}

Table 4. Time trend analyses of arrival dates before and after the piecewise regression breakpoints given in Table 1 of the Cuckoo and two of its hosts in Troms, northern Norway between 1980 and 2013. $\mathrm{n}=$ sample size and significant values $(\mathrm{p}<0.05)$ are shown in bold.

\begin{tabular}{|c|c|c|c|c|c|c|c|c|c|}
\hline \multirow[t]{3}{*}{ Species } & \multirow{3}{*}{$\begin{array}{l}\text { Break } \\
\text { point }\end{array}$} & \multicolumn{8}{|c|}{ Segmented piecewise regression (1980-2013) } \\
\hline & & \multicolumn{4}{|c|}{ Before break } & \multicolumn{4}{|c|}{ After break } \\
\hline & & Slope & $r^{2}$ & $\mathrm{p}$ & $\mathrm{n}$ & Slope & $\mathrm{r}^{2}$ & $\mathrm{p}$ & $\mathrm{n}$ \\
\hline Common Cuckoo & 1997 & -0.08 & 0.01 & 0.718 & 17 & -0.72 & 0.50 & 0.001 & 17 \\
\hline Dunnock & 1996 & -0.09 & 0.00 & 0.884 & 13 & -1.05 & 0.60 & 0.002 & 18 \\
\hline Brambling & 1999 & -0.55 & 0.17 & 0.007 & 20 & -1.74 & 0.54 & 0.000 & 15 \\
\hline
\end{tabular}


Brambling is (or has become - see Møller et al. 2011) a more important host for the Cuckoo in North Norway than in the rest of the country, there is thus no evidence of a progressive negative phenological mismatch between the Cuckoo and its hosts that may contribute to a decline in the Norwegian population of the former. One explanation may be that the implicit relationship between arrival date and laying date does not exist, as recently postulated by Dunn \& Møller (2014). As such, an early arrival of a host will not necessarily result in a mismatch in the laying dates of the host and Cuckoo Note, however, that Dunn \& Møller (2014) did find an advance in laying date in response to increasing temperature such that future climate change is still a potential driver of a phenological mismatch.

\section{REFERENCES}

Balmer, D.E., Gillings, S., Caffrey, B.J., Swann, R.L., Downie, I.S. \& Fuller, R.J. 2013. Bird Atlas 2007-11: the breeding and wintering birds of Britain and Ireland. BTO Books, Thetford.

Barrett, R.T. 2002. The phenology of spring bird migration to north Norway. Bird Study 49: 270-277.

Barrett, R. 2003. Tjelden er tilbake - snart er det vår! Vår Fuglefauna 26: 11-15.

Barrett, R.T. 2011. Recent response to climate change among migrant birds in northern Norway. Ringing and Migration 26: 83-93.

Douglas, D.J.T., Newson, S.E., Leech, D.I., Noble, D.G. \& Robinson, R.A. 2010. How important are climate-induced changes in host availability for population processes in an obligate brood parasite, the European Cuckoo? Oikos 119: 1834-1840.

Dunn, P.O. \& Møller, A.P. 2014. Changes in breeding phenology and population size of birds. Journal of Animal Ecology 83: 729-739.

Erritzøe, J. \& Mann, C.F. 2012. Cuckoos of the World. Methuen Drama. Downloaded from http://www. myilibrary.com? ID $=352280>$

Frantzen, B., Dransfeld, H. \& Hunsdal, O. 1991. Fugleatlas for Finnmark. Fylkesmannen i Finmark/Norsk Ornitologisk Forening, Avd. Finnmark, Vadsø.

Gjershaug, J.O., Thingstad, P.G., Eldøy, S. \& Byrkjeland, S. (eds.). Norsk fugleatlas. Norsk Ornitologisk Forening, Klæbu.

Jonzén, N., Lindén, A., Ergon, T., Knudsen, E., Vik, J.O., Rubolini, D., Piacentini, D., Brinch, C., Spina, F., Karlsson, L., Stervander, M., Andersson, A., Waldenström, J., Lehikoinen, A., Edvardsen, E., Solvang, R. \& Stenseth, N.C. 2006. Rapid advance of spring arrival dates in longdistance migratory birds. Science 312: 1959-1961.

Kålås, J.A., Husby, M., Nilsen, E.B. \& Vang, R. 2014. Bestandsvariasjoner for terrestriske fugler i Norge 1996-2013. Norsk Ornitologisk Forening Rapport 4-2014.

Moksnes, A. 2014. Hvor blir det av gjøken? Vår Fuglefauna 37:22-23.

Moksnes, A., Stokke, B.G. \& Røskaft, E. 2011. Gjøkens forunderlige verden. Tapir Akademisk Forlag, Trondheim.

Møller, A.P., Saino, N., Adamik, P., Ambrosini, R., Antonov, A., Campobello, D., Stokke, B.G., Fossøy, F., Lehikoinen, E., Martin-Vivaldi, M., Moksnes, A., Moskat, C., Røskaft, E., Rubolini, D., Schulze-Hagen, K., Soler, M. \& Shykoff, J.A. 2011. Rapid change in host use of the Common Cuckoo Cuculus canorus linked to climate change. Proceedings of the Royal Society, B 278: 733-738.

Rainio, K., Laaksonen, T., Ahola, M., Vähätalo, A.V. \& Lehikoinen, E. 2006. Climate responses in spring migration of boeal and arctic birds in relation to wintering area and taxonomy. Journal of Avian Biology 37: 507515.

Rubolini, D., Møller, A.P., Rainio, K. \& Lehikoinen, E. 2007. Intraspecific consistency and geographic variability in temporal trends of spring migration phenology among European bird species. Climate Research 35: 135-146.

Saino, N., Rubolini, D., Lehikoinen, E., Sokolov, L.V., Bonisoli-Alquati, A., Ambrosini, R., Boncoraglio, G. \& Møller, A.P. 2009. Climate change effects on migration phenology may mismatch brood parasitic cuckoos and their hosts. Biology Letters 5: 539-541.

Sparks, T.H., Roberts, D.R. \& Crick, H.Q.P. 2001. What is the value of first arrival dates of spring migrants in phenology? Avian Ecology and Behaviour 7: 75-85.

Strann, K.-B. \& Bakken, V. 2004. Hekkfuglatlas for Troms. Norsk Institutt for Naturforskning, Tromsø.

Received 30 April 2014. Accepted 6 June 2014 